\title{
ABORDAGEM INTERCULTURAL NA EDUCAÇ̃̃O EM CIÊNCIAS: DA ENERGIA PENSADA À ENERGIA VIVIDA
}

Rodrigo dos Santos Crepalde

Orlando Gomes de Aguiar Jr."

RESUMO: Este artigo tem duplo objetivo. A primeira contribuição é de ordem teórica. Partimos de referenciais teóricos que se definem no marco da educação intercultural, para justificarmos a ampliação da abrangência do referencial multi/intercultural para educação em ciências. Para tal, procuramos identificar em alguns autores e estudos no campo da educação em ciências uma proximidade com essa perspectiva. Do ponto de vista empírico, este artigo pretende examinar os sentidos produzidos ao conceito de energia, por estudantes de curso de licenciatura do campo, em narrativas por eles produzidas na atividade de encerramento de uma sequência didática forjada em uma perspectiva de educação intercultural. A produção escrita das narrativas foi marcada pela atitude ativa e responsiva dos estudantes ao demonstrar, especialmente, relações de "entrelaçamentos" entre as palavras alheias (da ciência escolar) e as suas próprias. Concluímos com algumas implicações para a pesquisa e a prática educativa, especialmente para o ensino de ciências.

Palavras-chaves: Educação Intercultural. Ensino de ciências. Conceito de energia. Cruzamento de fronteiras. Educação do campo.

\footnotetext{
* Doutorando em Educação pelo Programa de Pós-Graduação em Educação da Universidade Federal de Minas Gerais (UFMG); Professor Auxiliar no Instituto de Ciências Exatas, Naturais e Educação da UFTM (Universidade Federal do Triângulo Mineiro). E-mail: rodrigocrepalde@gmail.com

* * Doutor em Educação pela Universidade Federal de Minas Gerais e pós-doutorado em Educação em Ciências na Universidade de Leeds, Inglaterra; Professor Associado da Faculdade de Educação da UFMG E-mail: orlando@fae.ufmg.br
} 


\section{INTERCULTURAL APPROACH SCIENCE EDUCATION: FROM THOUGHT ENERGY TO LIVING ENERGY}

ABSTRACT: This paper has two purposes. The first one is a theoretical contribution. Starting from theoretical frameworks that define themselves in the context of intercultural education we justify the extension of the scope of multi/intercultural approaches to science education research. For such, we identify some authors and studies in the field of science education a closeness with this perspective. The second contribution is empirical and consist in examining the meaning of energy concept constructed by rural education students after a course oriented by an intercultural perspective. Data was collected in narratives produced by the students at the end of a teaching sequence about energy and environment. The production of written narratives was marked by active and responsive attitude of the students that indicate interweaving relationships between the words of others (science education) and their own. We conclude drawing some implications for research and educational practice, especially in science education.

Keywords: Intercultural education. Science education. Energy concept. Cultural border crossing.

\section{INTRODUC̣ÃO}

O reconhecimento do caráter multicultural da sociedade conduz ao entendimento da educação como espaço de encontros / desencontros culturais (CANEN, 1997). Se os sistemas educacionais fazem parte dessa realidade multicultural, é preciso afirmar práticas pedagógicas que façam esse movimento de reconhecimento dos diversos sujeitos que não compartilham do padrão dominante de cultura ocidental, branca, masculina, etc.

As proposições multi/interculturais já não se encerram em si mesmas, isto é, não estão contidas exclusivamente naqueles movimentos que reivindicam o seu reconhecimento étnico, de gênero, etc. Em primeiro lugar, não tem sentido falar de multi/interculturalidade sem pressupor um conjunto de inter-relações no âmbito tanto individual como coletivo, abertura ao diálogo com o outro, sínteses quando é possível produzi-las e respeito a olhares diferenciados de conceber a realidade. Além disso, os próprios movimentos sociais, frente à realidade multi/intercultural e aos desafios por ela colocados, não podem se fechar em si mesmos, sob pena de produzir mais segregação ${ }^{1}$. 
Desse modo, este artigo tem duplo objetivo. A primeira contribuição é de ordem teórica. Partimos de referenciais teóricos que problematizam e que se definem no marco da educação intercultural (SILVA, 2003; SOUZA \& FLEURI, 2003), multiculturalismo progressista (SANTOS, 2003), multiculturalismo crítico (MCLAREN, 1997) ou do multi/interculturalismo crítico (CANEN, 2000) para justificarmos a ampliação da abrangência do referencial multi/intercultural para educação em ciências, identificando em alguns autores uma proximidade com essa perspectiva. O entendimento da ciência escolar como uma cultura estrangeira para a grande maioria dos estudantes e a educação científica nas aulas de ciências como cruzamento de fronteiras rumo à subcultura da ciência (escolar) conduz nosso olhar no que chamamos de educação intercultural em ciências.

Do ponto de vista empírico, este artigo pretende examinar os sentidos produzidos ao conceito de energia, por estudantes de curso de licenciatura do campo, em narrativas por eles produzidas na atividade de encerramento de uma sequência didática forjada em uma perspectiva de educação intercultural.

Dada a centralidade do conceito de energia em um contexto de aprendizagem em ciências com fortes vínculos com os contextos de vida e trabalho dos educandos, privilegiamos as relações do conceito em seu domínio cotidiano e científico como meio de desenvolvimento do conceito para nossos sujeitos e convite ao diálogo, ao reconhecimento de suas vozes e da própria ciência, isto é, procurando a produção de novas sínteses a partir de um diálogo intercultural com as ciências.

\section{EDUCAÇÃO INTERCULTURAL EM CIÊNCIAS}

A intensificação dos cruzamentos entre culturas induz a ampliar o campo destas contribuições. Não se trata de "aplicar" os conhecimentos gerados por essas investigações, na sua maioria restritas à dinâmica interpessoal ou condicionadas pelos objetivos pragmáticos e pedagógicos da integração de minorias, a processos de mediação tecnológica e de escala transnacional. O crescimento de tensões em todas as áreas da vida social, em interações massivas entre sociedades, nas expansões do mercado e nos fracassos da política, está incorporando as perguntas sobre a interculturalidade a disciplinas que não usavam a expressão e reclamam novos horizontes teóricos. (CANCLINI, 2009, p. 24). 
Pretendemos construir um fio condutor estendendo e realizando um movimento de apropriação da abordagem multi/intercultural no campo da educação em ciências. Para tal empreitada recorreremos, sobretudo, a um autor, o canadense Glen Aikenhead, que tem reflexões e trabalhos sobre interculturalidade no campo da educação em ciências. Longe de esgotar o tema, também realizamos algumas aproximações com outros autores desse campo cujas abordagens são mais ou menos explícitas quanto à multi/interculturalidade nas aulas de ciências.

\subsection{PERSPECTIVA INTERCULTURAL E LETRAMENTO CIENTíFICO}

No prefácio de "Educação Científica para Todos", obra que adota uma perspectiva intercultural dirigida à educação científica para estudantes ocidentais em países industrializados, Aikenhead (2009) afirma que quanto mais desenvolvia sua sensibilidade cultural no ensino das ideias científicas em aulas com estudantes aborígenes, e quanto mais utilizava essas ideias para suas aulas não aborígenes, mais êxito obteve como professor de estudantes não aborígenes.

[...] o cruzamento cultural na educação científica está implícito no ensino de quase todos os estudantes (cerca de $90 \%$ deles) [...] a maioria dos estudantes não partilha, nem quer ser esclarecida em relação à cultura da ciência Ocidental. A educação científica baseada no cruzamento cultural não deve ser limitada aos estudantes aborígenes colonizados. (AIKENHEAD, 2009, p. 13).

Uma proposta de educação intercultural em ciências parte do reconhecimento da coexistência em um mesmo espaço de diversas culturas ou subculturas. Um indivíduo pode fazer parte de vários grupos ou subgrupos que transitam cotidianamente por várias subculturas (AIKENHEAD, 2009). Diferenças sociais, étnicas, de gênero, de gerações, religião, de pertencimento regional, entre outras, dão identidades a grupos, compartilhando múltiplos olhares e vozes sobre o mundo, que interagem dentro do espaço escolar.

A "literacia" científica ${ }^{2}$, letramento científico ou alfabetização científica (CACHAPUZ et al., 2005) tornou-se um slogan que orienta o desenvolvimento do currículo e a prática na sala de aula em todo mundo (AIKENHEAD, 2009). Nesse cenário, podemos entender o apelo de abordagens CTS (ciência, tecnologia, sociedade) como movimentos que pretendem contextualizar o ensino de ciências, ampliando suas propostas curriculares no sentido de reconhecer as necessidades sociais, políticas e econômicas de cada país. 
O futuro da educação em ciência residiria no desenvolvimento de um letramento científico para a obtenção de um público bem informado (AIKENHEAD, 2009). Seria, por exemplo, capacitar os cidadãos a enxergar as motivações políticas que estão por detrás do jargão científico, cálculos e previsões. Em decorrência, o letramento científico de cidadãos proporcionaria a capacidade de influenciar o conteúdo e as condições de participação nas tomadas de decisão sobre questões relacionadas com a ciência e tecnologia. "A ignorância ou medo da ciência e da tecnologia (isto é, a "iliteracia" científica) pode escravizar um cidadão numa servidão do século XXI". (AIKENHEAD, 2009, p. 20).

\subsection{O CRUZAMENTO DE FRONTEIRAS RUMO À SUBCULTURA DA CIÊNCIA}

A educação científica nas aulas de ciências pode ser compreendida em termos do cruzamento de fronteiras culturais, a partir das experiências vividas pelos estudantes dentro e fora de sala de aula, desde a subcultura dos seus colegas e das suas famílias até as subculturas da ciência e da ciência escolar (AIKENHEAD, 2009). Aikenhead, como outros autores no campo da educação em ciências, trabalha com uma perspectiva mais ampla que compreende o aprender ciência como aquisição de cultura.

Uma forma de ajudar os estudantes a movimentarem-se entre seu mundo cotidiano do senso comum e o mundo abstrato da ciência é tratar a ciência do ponto de vista que a maioria dos estudantes a concebe: a ciência como uma cultura estrangeira. (AIKENHEAD, 2009, p. 40, grifo nosso).

A ciência, dentro do marco da interculturalidade, é uma subcultura da cultura Ocidental ou Euro Americana. Os cientistas partilham um sistema de significados e de símbolos bem definido, com o qual interagem socialmente. "Este sistema foi institucionalizado na Europa Ocidental no século XVII e tornou-se, predominantemente, um sistema de significados e de símbolos ocidental, dominado pelo homem branco de classe média”. (AIKENHEAD, 2009, p. 95).

Por sua vez, poderíamos afirmar a existência de uma proximidade das subculturas da ciência e da ciência escolar num sentido de que a expectativa principal dos educadores em ciência é que os estudantes tomem para sua vida os "ensinamentos da ciência". Ao mesmo tempo, não podemos perder de vista que a subcultura da ciência escolar como campo complexo revela graus variáveis de autonomia de outras subculturas: relaciona-se com a subcultura da 
ciência, do país, da comunidade, da escola, da profissão docente, dentre outras. "A ciência escolar é uma força cultural poderosa em qualquer sociedade, diariamente incutida à força à maioria dos estudantes". (AIKENHEAD, 2009, p. 100).

Podemos fazer uma breve reflexão, inspirada na distinção que Candau (2000) realiza a partir de Forquim (1993) entre cultura escolar e cultura da escola. Para essa autora a cultura escolar é caracterizada pela normatização, homogeneização, "rotinização" e "didatização" porque se assenta sobre o currículo formal, os conteúdos, as competências, colocados intencionalmente pela escola como objetivos da aprendizagem. Por sua vez, a escola também é um "mundo social". A cultura da escola possui múltiplas vertentes da cultura vivida dos seus diferentes sujeitos que se inter-relacionam. Assim sendo, podemos também afirmar a existência de uma ciência escolar e de uma ciência da escola.

Podemos então caracterizar a cultura da ciência escolar como uma entidade mais estável, definida pelos objetivos da aprendizagem em ciência materializados em currículos, livros didáticos, etc. E a cultura da ciência da escola, caracterizada pelo seu modo particular de produção, circulação e consumo de significados mais próximos do mundo vivido. É importante ressaltar que essa breve reflexão das culturas ou subculturas na e da escola é menos uma busca das várias subculturas que coexistem nas aulas de ciências (dessa forma, poderia nos conduzir a um entendimento estático e "essencializado" desse ambiente), do que uma tentativa de expor a complexidade do "cruzamento de fronteiras" nas aulas de ciências, dado o entrelaçamento, capacidade de desdobramento, interpenetração e a relativa autonomia de cada uma dessas subculturas.

Para além das subculturas da ciência e da ciência escolar, os estudantes também participam numa série de outras importantes subculturas associadas à própria escola, aos seus grupos de pares, à família, aos meios de comunicação, entre outros. Essa participação em diferentes subculturas cria a necessidade do cruzamento entre suas fronteiras (AIKENHEAD, 2009). Por isso, o acesso ao conhecimento da ciência escolar ${ }^{3}$ é também visto como parte desses cruzamentos de fronteiras culturais, nos quais os educadores em ciência têm o papel de guias (facilitadores) desse cruzamento.

Nas nossas vidas diárias, de forma mais ou menos consciente, produzimos constantes mudanças de comportamentos à medida que nos deslocamos de um grupo de pessoas para outro, por isso, 
o cruzamento de fronteiras não necessita ser sempre tão problemático. A preocupação aqui reside em tornar visíveis esses cruzamentos não somente para os estudantes, mas para os próprios educadores.

Para alguns estudantes, os cruzamentos de fronteiras irão assemelhar-se a viagens guiadas fortemente estruturadas, tendo o professor como "guia", outros estudantes seriam como viajantes, tendo a intervenção de seus professores como um "agente de viagens", auxiliando na construção de pontes acadêmicas entre o conhecimento cotidiano e o científico; para outros estudantes, ainda, seria necessária uma verdadeira reconceitualização do território de ambos os lados das fronteiras (AIKENHEAD, 2009).

O professor como mediador cultural não forçaria a assimilação (etnocêntrica) da subcultura da ciência. Em lugar disso, baseado no cruzamento cultural, seu objetivo seria o de promover, nas aulas de ciências, o reconhecimento das características da subcultura da ciência e efetuar cruzamentos culturais para o interior e para o exterior dessa mesma subcultura, tornando essas transições "movimentos bem suaves" (AIKENHEAD, 2009).

Os cruzamentos de fronteiras poderão ser mais acessíveis nas aulas estudandose as subculturas das vidas cotidianas dos estudantes e contrastando-as com uma análise crítica da subcultura da ciência (as suas normas, valores, crenças, expectativas e ações convencionais), permitindo aos estudantes moverem-se conscientemente entre o mundo da vida cotidiana e o da ciência, alternando entre convenções linguísticas, conceitualizações, valores, epistemologias explícitas, mas sem que seja necessária a adoção de uma forma de conhecer científica por parte dos estudantes. Esta regra da "não assimilação" não impede que os professores cativem o interesse e a curiosidade dos estudantes pela ciência, fazendo um bom trabalho no ritual de passagem até a subcultura da ciência. (AIKENHEAD, 2009, p. 135).

\subsection{DOMÍNIOS DO CONHECIMENTO COTIDIANO E CIENTÍFICO: ENTRE A CHAMA E 0 CRISTAL}

Solomon $(1983,1992)$ discute a existência de dois domínios do conhecimento: o cotidiano e o científico. Estes domínios podem existir paralelamente e não é objetivo do ensino de ciências mover os estudantes permanentemente de um domínio a outro, mas habilitá-los a reconhecer os significados cotidiano e científico como duas formas de olhar sobre o mundo. Segundo a autora, eliminar o significado cotidiano impossibilitaria o diálogo do estudante com o mundo, conclusão em consonância com a perspectiva intercultural adotada nessa pesquisa. 
É importante destacar que ao afirmarmos junto com outros autores os domínios do conhecimento cotidiano e científico não queremos com isso reduzir a produção de conhecimento da vida social a duas formas estaticamente opostas. Pelo contrário, nossa intenção é: 1) reconhecer dois campos distintos de significação ou da linguagem humana (o cotidiano e o científico, ou mais precisamente nesse último caso, o científico escolar); 2) destacar essas formas "radicalmente diferentes de construir a realidade discursivamente", isto é, o cotidiano marcado por narrativas (sequência linear de eventos, presença de narradores), mais próximo da fala, que não precisa de uma reflexão permanente, mundo vivo preenchido de acontecimentos, como em uma "chama". E o científico, próximo da linguagem escrita, de indispensável reflexão do seu uso, em que o sujeito está oculto (por isso, sua aparente neutralidade) e que os acontecimentos e processos são congelados (sua nominalização, substituição de verbos que expressam ações por grupos nominais, aumento da densidade léxica de seus termos), pois é preciso inseri-los em estruturas para sua inteligibilidade, como num "cristal" (MORTIMER, 1998); E por fim, 3) afirmar a necessidade de seu encontro-confronto dialógico, pois, "através do diálogo, a chama poderá dissolver a rigidez do cristal sem destruí-lo. Infiltrando-se em seus interstícios como luz e movimento, projetará as imagens de uma nova sociedade, mais justa e mais próxima da natureza”. (MORTIMER, 1998, p. 104; p. 117).

\subsection{INTERROGAR A INVISIBILIDADE DO SABER CIENTÍFICO E A TOMADA DE DECISÃO DO "PÚBLICO"}

Buscamos, então, uma orientação para a educação intercultural em ciências que, de um lado, relativize a ciência sem dissolvê-la em um relativismo estéril, e de outro lado, reconheça e dê "potência" ao conhecimento cotidiano sem engessá-lo. Tratar a ciência como subcultura é reconhecer sua potência e, ao mesmo tempo, sua debilidade em nossa sociedade contemporânea. Explicitar seu contexto de aplicação discursiva faz parte desse movimento de relativização. De uma forma isolada a ciência ocidental pode ser entendida apenas como uma forma de saber dentre várias outras. Mas, ao perder de vista as condições e as relações de poder dessa produção, ou em outras palavras, o seu caráter ideológico em nossa sociedade contemporânea, estaríamos contribuindo (mesmo que a intenção seja o oposto) para reforçar sua pretensa objetividade e neutralidade, marcas do poder e autoridade daqueles que dominam seus códigos. 
Nesse sentido, o conceito de ciência, da ciência ocidental, precisa ser reconhecido como uma das formas de saber, uma das formas de abordar a realidade. Além disso, não como qualquer forma de conhecimento, mas como forma hegemônica da civilização ocidental que impõe, com seu discurso de poder, sua racionalidade. Sua invisibilidade precisa ser combatida e sempre interrogada criticamente como experiência de descentramento.

Paula \& Lima (2007) discutem a (im)pertinência do letramento científico à luz da crítica de que as metas da educação em ciências estão para além desse letramento, ou seja, é necessário aprender ciências e sobre as ciências (sua natureza como uma das formas de saber, seus contextos de aplicação e validade); e em termos da noção esvaziada de cidadania que reduz o social ao individual (por exemplo, quando a responsabilidade de escolha dos governantes e parlamentares é tratada como uma mera questão do voto individual) e de liberdade reificada pela ideia de possibilidade de consumo (a cidadania é reduzida a "direitos do consumidor").

[...] o ensino focado apenas nos produtos das Ciências inibe diversas contribuições potenciais da educação escolar para a formação de sujeitos críticos e capazes de exercer alguma autonomia intelectual para superar a tendência da cultura contemporânea de pasteurizar identidades e privatizar os problemas humanos, retirando sua dimensão social e econômica. (PAULA \& LIMA, 2007, p. 7).

A visão de sociedade "centrada na ciência" ou de "esclarecimento", isto é, a racionalidade científica, certificadora do progresso, única possibilidade para o desenvolvimento social, "positivamente", postula a ignorância ou irracionalidade dos não especialistas na tomada de decisões, desautorizando suas vozes em assuntos sociocientíficos, bem como impedindo sua participação democrática (IRWIN, 1995; LIMA, 2011).

Se, por um lado, compreendemos a ciência como uma prática social condicionada pelo contexto em que se desenvolve, rompendo com uma visão de que o conhecimento científico é universal e livre de valores, de outro também, devemos realizar esse mesmo movimento em relação ao "público" (IRWIN, 1995; GARCIA, 2010). A pretensa homogeneidade atribuída à ciência também etnocentricamente estende-se a considerações sobre o "público", isto é, aqueles "não cientistas" que estão afastados do campo científico mais amplo.

Este conjunto impreciso de "não científicos" ou "leigos", foi considerado como mero consumidor de conhecimento com um relativo interesse em melhorar a sua "alfabetização científica". Desta forma, a condição de "não-científico" se associava, desde a perspectiva clássica, com a condição de receptores passivos. 
Por um lado, a ciência como um emblema de autocrítica e reflexão permanentes, pelo outro, o público desprovido de ferramentas para apreendê-la. (GARCIA, 2010, p. 163, tradução nossa).

Essa concepção trata o "público" como pessoas que não têm capacidade crítica em relação ao conhecimento científico, negando, assim, qualquer possibilidade de que elas tenham alguma contribuição não só sobre a ciência, mas nas aulas de ciências, na escola, na comunidade, na sociedade. A distinção entre "sábios" ${ }^{\mathrm{e}}$ "leigos" não permite concluir que um grupo é mais capaz para definir as necessidades vinculadas com a ciência nas sociedades modernas.

Aqueles que proclamam um período de incubação ética para preparar homens e mulheres para a cidadania política são também aqueles que negam aos povos colonizados o direito de autogovernar-se até que sejam "civilizados" o suficiente para exercê-lo responsavelmente. Eles desprezam o fato de que, de longe, a melhor preparação para a independência política é a independência política. (EAGLETON, 2011, p. 17).

Parafraseando Eagleton, a melhor preparação para tomada de decisões científicas é a tomada de decisões científicas.

\section{CARTA À LILIANE: OS ENUNCIADOS DOS SUJEITOS DA LICENCIATURA EM EDUCACุÃO DO CAMPO}

O curso de Licenciatura em Educação do Campo (Lecampo ${ }^{6}$ oferecido pela Faculdade de Educação da Universidade Federal de Minas Gerais (UFMG) tem duração de 08 semestres e conta com módulos presenciais semestralmente realizados nos meses de fevereiro e julho. Os módulos presenciais são conhecidos como períodos de Tempo Escola (TE). Entre dois módulos presenciais ocorre um período denominado Tempo Comunidade (TC), no qual os alunos permanecem em suas comunidades de origem enquanto realizam algumas tarefas escolares orientadas. O curso oferece quatro habilitações: Matemática (MAT), Ciências Sociais e Humanidades (CSH), Línguas, Artes e Literatura (LAL) e Ciência da Vida e da Natureza (CVN), para atuação nas séries finais do Ensino Fundamental e Ensino Médio.

Como primeira oferta na modalidade de curso regular de Licenciatura em Educação do Campo, habilitação ciências da vida e da natureza, acompanhado do processo seletivo via vestibular como os demais cursos da universidade, a intencionalidade dos seus candidatos ao procurar o curso foi demarcada por um olhar mais ou 
menos orgânico com o campo, seja por uma origem a ser retomada mais adiante como forma de retorno pelo esforço de escolarização alcançado ou pelos laços concretos da vida no campo e/ou sua participação em movimentos sociais. De todo modo, os estudantes ligados diretamente ou não ao campo compartilham uma diversidade de trajetórias, perspectivas e objetivos.

A coleta de dados ocorreu em 02 (dois) períodos, em Julho de 2010 e Fevereiro 2011. Acompanhamos 03 (três) módulos relacionados ao conceito de energia que foram desenvolvidos em uma turma de CVN. Em cada módulo, participamos do planejamento, organização e desenvolvimento das atividades. As aulas foram filmadas em vídeo e os materiais produzidos pelos estudantes reproduzidos para análise posterior.

Em julho de 2010, acompanhamos o módulo "Energia e ambiente", conduzido por um professor da universidade ligado à Faculdade de Educação, que tinha como objetivos a apresentação e discussão das diversas fontes, formas, manifestações e usos de energia; a compreensão dos processos de transformação, conservação e degradação de energia; o uso racional de energia, problemas sociais e ambientais ligados à produção e ao consumo de energia nas sociedades modernas; a descrição e obtenção de novas fontes e alternativas energéticas; a discussão das relações entre ciência, tecnologia, sociedade e cidadania. A atividade de fechamento deste módulo será apresentada a seguir.

O objetivo da atividade final deste módulo foi o de obter uma síntese, através do recurso da narrativa, da aprendizagem dos aspectos do conceito científico de energia. Nessa atividade, os estudantes foram orientados a elaborar uma carta a uma colega (estudante de graduação e monitora da turma, com quem os alunos tinham grande afinidade), que por problemas pessoais não compareceu às aulas do módulo, expondo a ela o que de mais significativo foi desenvolvido no curso. O propósito desta atividade foi o de desencadear, nos sujeitos, uma reflexão e síntese sobre o que aprenderam e, assim, tornar disponíveis as relações que os estudantes estabeleciam (de reconhecimento, estranhamento, encantamento, incompreensão ou recusa) com aspectos do conceito científico de energia. Neste artigo, escolhemos transcrever por completo 2 (duas) cartas produzidas pelos estudantes.

Antes de partimos à análise das narrativas produzidas pelos estudantes é importante enfatizar o modo como os sujeitos apropriam-se da "palavra alheia", no sentido bakhtiniano, produzindo novos modos de dizer, isto é, hibridismos entre 
suas vozes e a da ciência escolar. Nessa direção, encontramos no trabalho de Fontana (1996), que procura entender o modo como se desenvolve o processo de apropriação do conceito de "cultura" por crianças do $4^{\circ}$ ano, possíveis caracterizações das novas relações criadas entre as palavras dos sujeitos e a "palavra alheia" a partir do ensino de um conceito escolar.

Essa autora discute três modos da relação entre a palavra alheia e o sujeito falante: o assentimento, os entrelaçamentos e o questionamento. $\mathrm{Na}$ relação de assentimento o dizer do professor (da ciência escolar) é dominante no discurso dos estudantes, pelo menos nos enunciados presentes nas produções escritas solicitadas em um contexto escolar específico. Nos entrelaçamentos torna-se visível a presença de outra voz, a do estudante. Seus dizeres, por exemplo, entrelaçam-se com a voz canonizada da ciência escolar, produzindo ressignificações no discurso marcadas pela sua posição ativa e responsiva (BAKHTIN, 2011). Por sua vez, na relação de questionamento também emerge a voz do professor (da ciência escolar), mas ela é questionada pela voz do sujeito ao ponto de criar novas possibilidades ou outras análises (FONTANA, 1996).

\section{CARTA I?:}

Belo Horizonte, 26.07.10

Oi Liliane ${ }^{8}$, tudo bem?

O objetivo desta carta é te falar sobre energia e ambiente, tema das aulas de Física do nosso curso.

Durante as aulas, estudamos vários tipos de energia, dentre eles:

Energia potencial gravitacional que está relacionada com altura e massa de um determinado corpo. Um objeto deixado a determinada altura possui energia potencial gravitacional à medida que ele cai dessa altura ela passa a se transformar em energia cinética que esta relacionada com o movimento e as transformações de energia ocorrem até o objeto chegar ao chão.

Energia química esta relacionada com aquela que recebemos em nosso corpo através da alimentação e também a energia contida em pilhas e baterias.

É interessante você saber querida Liliane que a eficiência é um modelo que ajuda a explicar o fato de que a energia nunca acaba, ela é transferida a outro objeto ou transformada em outro tipo de energia e passada para o meio ambiente.

Por exemplo: dos 100\% de energia para fazer funcionar uma lâmpada apenas $3 \%$ é transformada em energia luminosa, os outros $97 \%$ é passado ao meio ambiente na forma de calor.

Falamos também sobre energia elástica que é, por exemplo o movimento feito pelo garoto ao esticar a borracha de um estilingue ou o movimento da mola. 
Outra coisa que gostaria de te falar é que é muito importante evitar o desperdício de energia com o consumo tanto de energia quanto dos produtos que demandam uma grande quantidade de energia para serem fabricados. Pois cada vez que você joga uma lata de refrigerante no lixo está jogando fora, toda energia gasta para produzi-la, portanto, quanto menos consumimos mais energia economizamos.

Espero que as informações contidas nesta carta te ajude a compreender alguns conceitos de energia e a importância de economizá-la.

Qualquer dúvida, tenho um ótimo professor [...] que pode te auxiliar na compreensão do assunto.

Um grande abraço

Da sua amiga, Iris.

Destacamos no discurso do sujeito:

1. "O objetivo desta carta é te falar sobre energia e ambiente, tema das aulas de Física do nosso curso." O discurso evolui ancorado nas manifestações de energia, mediado pelo conceito de degradação e transformação de energia, e culmina na preocupação com o meio ambiente (espécie de síntese das atividades e discussões ocorridas ao longo da disciplina "Energia e ambiente").

2. O conceito de eficiência, mais do que um conceito cotidiano, possui uma significação própria da ciência, isto é, “[...] é um modelo que ajuda a explicar o fato de que a energia nunca acaba, ela é transferida a outro objeto ou transformada em outro tipo de energia e passada para o meio ambiente".

3. O "modelo" de eficiência encontra seu lugar para o sujeito e orienta seu discurso (BAKHTIN/VOLOCHINOV, 2010), isto é, produz entrelaçamentos entre a fala da ciência e a da estudante: "Pois cada vez que você joga uma lata de refrigerante no lixo está jogando fora, toda energia gasta para produzi-la, portanto, quanto menos consumimos mais energia economizamos."

4. A conclusão, logo após exposição no domínio científico, marca um retorno ao cotidiano potencializado pela ideia científica, nesse caso de degradação, ao problematizar a relação entre demanda de energia e consumo, ou seja, de discussão do uso social de energia. A estudante espera que a leitura de sua carta possibilite a compreensão de alguns conceitos e (adição que não se reduz a uma mera complementaridade) "[...] a importância de economizá-la”. 


\section{CARTA II:}

Carta para Liliane

Querida Liliane venho através desta carta, contar os conceitos essenciais trabalhado nas aulas do professor [...] e seu auxiliar [...], voltado pra o ensino de Física.

Partimos do princípio do que é energia? As respostas dessa pergunta veio ao desenrolar da disciplina.

Bom, trabalhamos, várias formas de presença de energia. Como elas são geradas, como podem ser transformada.

Exemplo dessa energia posso citar a "Química", ou seja, energia potencial química, que é a energia dos minerais e dos alimentos, que parte do principio do sol como ponto de partida de transformação energética.

Vimos que a energia química pode se transformar em outras diversas, como energia elétrica, térmica, luminosa, mecânica dentre outras.

Trabalhamos energia elétrica gerada a partir de hidrelétricas. Encima de hidrelétricas fizemos debates sobre a prevista usina de Belo Monte.

Vimos como é feito cálculos kWh usando diversas formas. Trabalhando dentro da temática de como trabalhar esse tipo de disciplina com nossos futuros alunos.

Importante lembrar que quase todo tipo de energia pode ser transformada mas nunca perdida.

Dentre essas transformações de energia, a que mais gerou debate foi a transformação de energia potencial gravitacional em energia cinética.

Enfim foram aulas muito diferenciadas, trabalhando dentro de uma temática especial, acredito eu que fora um desafio para o professor trabalhar dentro de uma temática voltada para o campo. Mas devo leva em consideração que para mim também foi um desafio e tanto absorver conhecimento com uma visão diferente.

Bom foi mais ou menos isso aí. Se você ver aquele doido do Professor por aí, por favor dê parabéns a ele por conseguir alcançar uma metodologia tão diferenciada de trabalhar e despertar a curiosidade de seus alunos. Para ser um bom profissional, é preciso que seja diferente. Creio que ele conseguiu passar isso para a turma.

Há fala pro Pesquisador que ele é gente boa também.

Gustavo.

Destacamos no discurso do sujeito:

1. O ponto de partida foi a conceitualização da energia que só veio a concretizar-se no "desenrolar" do curso.

2. Percebemos um movimento do discurso cotidiano ao científico, a partir de uma transição das vozes que o sujeito mobiliza para demonstrar a apropriação do conceito (entrelaçamentos). Por exemplo, a referência a "formas de presença de energia", ao tratar das manifestações de 
energia é marcado pelo discurso cotidiano que, pouco a pouco, entrelaça-se ao científico. Ao introduzir o exemplo da energia química ("Química', ou seja, energia potencial química, que é a energia dos minerais e dos alimentos, que parte do principio do sol como ponto de partida de transformação energética.”), o processo de transformação tendo o sol como fonte primária, a medida ("Vimos como é feito cálculos kWh usando diversas formas.") e a conservação de energia.

3. Outra marca singular do discurso deste estudante é a preocupação e o significado da reflexão pedagógica, particularmente em relação à educação para o campo: "Enfim foram aulas muito diferenciadas, trabalhando dentro de uma temática especial, acredito eu que fora um desafio para o professor trabalhar dentro de uma temática voltada para o campo". Tal discurso revela que o estudante toma por objeto do curso de formação tanto os aspectos de conteúdo científico quanto aqueles relacionados à metodologia de ensino.

4. "Mas devo leva em consideração que para mim também foi um desafio e tanto absorver conhecimento com uma visão diferente." Nas palavras de Aikenhead (2009), o estudante parece se deparar com uma cultura estrangeira, numa relação de diálogo produtivo e respeitoso, mas de um conhecimento que ainda não lhe pertence inteiramente. Parece indicar o processo de tomada de consciência do cruzamento de fronteiras pelo estudante.

\section{CONSIDERACְÕES FINAIS}

Nosso esforço de sistematização, mesmo que a título de um esboço parcial, das produções no campo da educação em ciências, mais ou menos declaradas interculturais, e a aproximação desses trabalhos com a área mais ampla da pesquisa intercultural reforçaram nossa convicção de que a interculturalidade no ensino de ciências é menos uma exigência externa imposta por outros campos do conhecimento do que uma necessidade nas aulas de ciências em construir um ensino culturalmente sensível que se dispõe ao diálogo entre as ciências e as vivências dos estudantes. 
O movimento em que se reconhece o conhecimento referente ao vivido como conhecimento legítimo, passo sine qua non para interculturalidade, a partir do diálogo dos significados cotidianos e científicos da palavra energia, também contribuiu para o desenvolvimento, no sentido de um movimento vivo de generalização que ascende ao concreto ${ }^{9}$, do conceito científico de energia.

O pressuposto intercultural, tanto do curso de Licenciatura do Campo como das nossas intenções de pesquisa, favoreceu, sobretudo, a observação e o desenvolvimento de relações de "encontro" entre as vivências dos estudantes do campo e a ideia científica de energia. Desse modo, a produção escrita das narrativas foi marcada pela atitude ativa e responsiva dos estudantes ao demonstrar, especialmente, relações de "entrelaçamentos" entre as palavras alheias (da ciência escolar) e as suas próprias.

Por fim, uma reflexão necessária, entretanto incompleta e parcial, dos caminhos que trilhamos dentro da perspectiva intercultural que assumimos desde o início de nosso trabalho. Ao pensarmos processos de "enculturação" (progressiva socialização em uma cultura) nas aulas de ciências, temos em mente a acentuação do caráter cultural do aprender ciências, sem o desconhecimento de sua natureza ideológica. Assim, nossa expectativa é, progressivamente, conduzir (como um "guia") os estudantes por um mundo preenchido por modelos, estruturas conceituais, matematizações e abstrações, a fim de que eles extraiam dessa "viagem" ensinamentos para sua vida (sem, é claro, terem que abandonar suas crenças, valores, etc.). Mas desse modo, corremos o risco de engessar a subcultura da ciência (escolar) e as subculturas nas quais todos nós, e não apenas os estudantes, transitamos todos os dias, ao substancializá-las, ao tratálas como "pacotes" de conhecimentos disponíveis em "prateleiras", distribuídas em diferentes "alturas e seções". Ao mesmo tempo, não podemos perder de vista processos de "aculturação" (interação entre culturas), mesmo que indissociáveis e articulados a processos de "enculturação". $\mathrm{Na}$ "aculturação", também se acentua o caráter cultural do aprender ciências, mas sua centralidade está nos processos de interação entre as várias (sub)culturas que podem, até mesmo, serem transformadas ou revolucionadas.

Em termos bakhtinianos, a experiência discursiva individual se dá em contínuo contato com os enunciados dos outros, assim, nosso discurso é, mais ou menos, carregado de alteridade, de aperceptibilidade e relevância (BAKHTIN, 2011). Se a enculturação nas ciências nos introduz em um novo gênero discursivo 
em termos normativos (pois ele não é criado, mas dado ao sujeito), ela produz a possibilidade de descobrirmos, pelo domínio do novo gênero, criativamente, nossa individualidade. Assim, no processo de aculturação, além de não transitarmos mais da mesma forma pelas diferentes subculturas, descobrimos, rejeitamos, produzimos, reelaboramos e ressignificamos outras tantas subculturas.

\section{REFERÊNCIAS}

ADORNO, Theodor W.; HORKHEIMER, Max. Dialética do esclarecimento. Rio de Janeiro: Zahar, 1985. p. 7-16.

AIKENHEAD, Glen S. Educação cientifica para todos. Trad. Maria Teresa Oliveira. Lisboa: Edições Pedago, 2009.

ALFARO, Santiago; ANSIÓN, Juan; TUBINO, Fidel (Orgs.). Ciudadanía intercultural: conceptos e pedagogías desde a América Latina. Lima: Fondo Editorial, 2008. p. 9-25.

ARNAY, José. Reflexões para um debate sobre a construção do conhecimento na escola: rumo a uma cultura científica escolar. In: RODRIGO, Maria José \& ARNAY, José (Orgs.). Conhecimento cotidiano, escolar e cientifico: representação e mudança. São Paulo: Ática, 1998. p. 37-73.

BAKHTIN (VOLOCHINOV), Mikhail. Marxismo e filosofia da linguagem. São Paulo: Hucitec, 2010.

BAKHTIN, Mikhail. Estética da criação verbal. São Paulo: Martins Fontes, 2011. p. XXXIIIXXXIV, p. 261-306, p. 393-410.

CACHAPUZ, Antônio et al. A necessária renovação do ensino das ciências. São Paulo: Cortez, 2005.

CANCLINI, Nestor García. Diferentes, desiguais e desconectados. Rio de Janeiro: Editora UFRJ, 2009.

CANEN, Ana. Formação de professores e diversidade cultural. In: CANDAU, Vera Maria (Org.). Magistério: construção cotidiana. Petrópolis: Vozes, 1997. p. 205-236.

CANEN, Ana. Educação multicultural, identidade nacional e pluralidade cultural: tensões e implicações curriculares. Cadernos de Pesquisa, n. 111, p.135-149, dez. 2000.

EAGLETON, Terry. A ideia de cultura. São Paulo: Editora UNESP, 2005.

FORQUIM, Jean-Claude. Escola e cultura: as bases sociais e epistemológicas do conhecimento escolar. Porto Alegre: Artes Médicas, 1993. p. 137-143, 163-173.

GARCIA, Marisa C. Percepción pública de la ciencia: ¿Qué ciencia?; ¿Qué público? Una aproximación al impacto de los enfoques etnográficos en los estudios de percepción pública de la ciencia. Ensaio Pesquisa em Educação em Ciências, v. 12, n. 1, p. 1-16, 2010.

IRWIN, A. Ciência cidadã: um estudo das pessoas; especialização e desenvolvimento sustentável. Lisboa: Piaget, 1995.

LIMA, Maria Emília Caixeta de Castro. Tensões emergentes da educação do campo em torno da construção do conbecimento. In: Simpósio 40 anos do Programa de Pós-graduação em Educação da Faculdade de Educação - UFMG, 2011. (Palestra).

MCLAREN, Peter. Multiculturalismo crítico. São Paulo: Cortez, 1997.

MORTIMER, Eduardo Fleury. Sobre chamas e cristais: a linguagem cotidiana, a linguagem científica e o ensino de ciências. In: CHASSOT; OLIVEIRA, Renato José de (Orgs.). Ciência, ética e cultura na educação. São Leopoldo: Editora UNISINOS, 1998. p. 95-118. 
PAULA, H. F.; LIMA, M. E. C. C. Educação em ciências, letramento e cidadania. Química Nova na Escola, v. 25, p. 3-9, 2007.

POZO, Juan Ignácio; CRESPO, Miguel Angel Gomes. A aprendizagem e o ensino de ciências: do conhecimento cotidiano ao conhecimento científico. Porto Alegre: Artmed, 2009.

SANTOS, Boaventura de Sousa. Por uma concepção multicultural de direitos humanos. In: SANTOS, Boaventura de Sousa (Org.). Reconhecerpara libertar: os caminhos do cosmopolitismo multicultural. Rio de Janeiro: Civilização Brasileira, 2003. p. 427-462.

SILVA, Gilberto Ferreira da. Multiculturalismo e educação intercultural: vertentes históricas e repercussões atuais na educação. In: FLEURI, Reinaldo Matias (Org.). Educação Intercultural: mediações necessárias. Rio de Janeiro: DP\&A, 2003.

SOLOMON, Joan. Learning about energy: how pupils think in two domains. European Journal of Science Education, v. 5, n. 1, p. 49-59, 1983.

SOLOMON, Joan. Getting to know about energy: in school and society. London; Washington, D.C.: Falmer Press, 1992.

SOUZA, Maria Izabel Porto de; FLEURI, Reinaldo Matias. Entre limites e limiares de culturas: educação na perspectiva intercultural. In: FLEURI, Reinaldo Matias (Org.). Educação intercultural: mediações necessárias. Rio de Janeiro: DP\&A, 2003. p. 53-84.

UNIVERSIDADE FEDERAL DE MINAS GERAIS. Edital para os cursos de Licenciatura em Educação do Campo e Licenciatura Intercultural para educadores Indígenas da UFMG 2012. Belo Horizonte, 2011.

\section{NOTAS}

${ }^{1}$ Por exemplo, no caso de povos indígenas da América Latina busca-se uma educação cidadã intercultural para todos, indígenas e não indígenas, que questione também as condições sociais que legitimam a discriminação, a injustiça e as desigualdades (ALFARO et al., 2008). 2 Aikenhead utiliza originalmente o termo "literacy", que foi traduzido por Maria Teresa Oliveira por "literacia", da edição portuguesa de "Educação Científica para Todos", Lisboa, Edições Pedago, 2009.

${ }^{3}$ Nosso entendimento do acesso ao conhecimento da ciência escolar se aproxima das reflexões de Arnay (1998) sobre a construção do conhecimento na escola: "A cultura científica escolar de que falo é necessária como conhecimento específico diferenciado, tanto do conhecimento cotidiano como do propriamente científico. Trata-se de estabelecer um espaço intermediário no qual os processos de ensino traduzam e tornem compatíveis as concepções cotidianas implícitas com aspectos conceituais tácitos de maior complexidade, parte dos quais poderiam ser adaptações ajustadas e simplificadas da estrutura histórica e conceitual da ciência, porém sem oferecer o conhecimento científico como único modelo e meta do conhecimento escolar". (ARNAY, 1998, p. 48, grifos do autor).

${ }^{4}$ Adorno e Horkheimer, em "Dialética do Esclarecimento", ao se referirem à mistificação do esclarecimento sob a forma da ciência positiva, afirmam em seu prefácio: "Não alimentamos dúvida nenhuma - e nisso reside nossa petitio principii - de que a liberdade na sociedade é inseparável do pensamento esclarecedor. Contudo, acreditamos ter reconhecido com a mesma clareza que o próprio conceito desse pensamento, tanto quanto as formas históricas concretas, as instituições da sociedade com as quais está entrelaçado, contêm o germe para a 
regressão que hoje tem lugar por toda a parte. Se o esclarecimento não acolhe dentro de si a reflexão sobre esse elemento regressivo, ele está selando seu próprio destino. Abandonando a seus inimigos a reflexão sobre esse elemento destrutivo do progresso, o pensamento cegamente pragmatizado perde seu caráter superador e, por isso, também sua relação com a verdade". (ADORNO \& HORKHEIMER, 1985, p. 13).

$\mathbf{5}$ Tradução para “científicos” no texto de GARCIA (2010).

6 “O curso de Licenciatura em Educação do Campo habilita professores para atuar nos últimos quatro anos do Ensino Fundamental e Médio, [...] [nas habilitações específicas], em escolas que atendem as populações do campo. São consideradas como escolas do campo aquelas que têm sua sede no espaço geográfico classificado pelo Instituto Brasileiro de Geografia e Estatística como rural, e, mais amplamente, aquelas escolas que, mesmo tendo sua sede em áreas consideradas urbanas, atendem a populações cuja dinâmica social e cultural está majoritariamente vinculada ao trabalho no campo." (UNIVERSIDADE FEDERAL DE MINAS GERAIS, 2011, p. 1).

${ }^{7}$ Mantemos a escrita dos sujeitos tal como foi produzida, sem correções de ortografia ou sintaxe conforme norma culta da língua portuguesa. Com isso, procuramos preservar os enunciados dos sujeitos em sua forma e conteúdo (perdendo apenas a composição e estética da escrita no papel).

8 Para preservar a identidade dos sujeitos, tanto nas cartas e interações em sala de aula, optamos por trabalhar com nomes fictícios. Do mesmo modo, também adotamos o nome de Professor ou Pesquisador, inclusive nas situações que os estudantes utilizavam seus nomes.

${ }^{\mathbf{9}}$ Dialeticamente, podemos pensar o desenvolvimento dos conceitos cotidiano e científico como processo que vai da abstração à ascensão ao concreto. $\mathrm{O}$ concreto pensado, resultado da reflexão e da elaboração a partir dos conceitos científicos, conduz ao novo concreto, síntese de múltiplas determinações, num movimento de idas e voltas em espiral.

Recebido: $12 / 08 / 2013$

Aprovado: 03/06/2014

Contato:

Universidade Federal de Minas Gerais, Faculdade de Educação Departamento de Métodos e Técnicas de Ensino Av. Antônio Carlos, 6627 - Bairro Pampulha Belo Horizonte | MG | Brasil CEP 31.270-901 